\title{
Mitochondrial DNA Evidence and Evolution in Varanoidea (Squamata)
}

\author{
Jennifer C. Ast \\ Museum of Zoology, University of Michigan, Ann Arbor, Michigan 48109 \\ Accepted May 20, 2001; published online November 19, 2001
}

\begin{abstract}
Varanoidea is a monophyletic group of anguimorph lizards, comprising the New World helodermatids, the Bornean earless monitor Lanthanotus borneensis, and the Old World monitors (Varanus). I use mitochondrial DNA sequences and extensive taxonomic sampling to test alternative hypotheses of varanoid relationships. The most parsimonious hypothesis confirms the monophyly of Varanoidea (Heloderma, Lanthanotus, and Varanus) and Varanus, as well as the sister-taxon relationship of Varanus and Lanthanotus. The relationships among Varanus species differ in several respects from previous hypotheses. Three major lineages are recognized within Varanus: an African clade basal to the rest of the group, an Indo-Asian clade, and an Indo-Australian clade. Within the last lineage, the endemic Australian dwarf monitors ( 0 datria) form a clade sister to the large Australian monitors (the gouldii group). Tests of the effects of rate heterogeneity and homoplasy demonstrate that putative process partitions of data are largely congruent with one another and contribute positive support to the overall hypothesis. @ 2001 The Willi Hennig Society
\end{abstract}

\section{INTRODUCTION}

Varanoidea is an ancient group of anguimorph lizards, comprising the two extant New World helodermatids (Heloderma horridum and Heloderma suspectum), the Bornean earless monitor (Lanthanotus borneensis), and the Old World monitors (Varanus). The earliest fossils that can be clearly assigned to this group include the Middle Cretaceous aigialosaurs (Carroll and deBraga, 1992); later varanoid fossils include the helodermatid-like monstersaurians Gobiderma and Estesia (Norell and Gao, 1997), the Lanthanotus-like Cherminotus (Gao and Norell, 2000), and the Varanuslike Saniwides and Telmasaurus (Pregill et al., 1986). Currently, approximately 50 extant species of Varanus are recognized (Table 1). These species are found in Africa; central and southern mainland Asia and Malaysian and Indonesian islands (these may be roughly described as the Indo-Asian species); and Papua New Guinea and Australia (where more than half the species are found, henceforth referred to as the Indo-Australian species). All monitors share a basic body plan and several morphological synapomorphies, yet the impressive diversity achieved by Varanus within its rather conservative overall morphology makes it an ideal radiation for investigating and comparing the evolution of features such as gross morphology (e.g., Pianka, 1995), habitat and ecology (e.g., Losos and Greene, 1988), and physiology (e.g., Bartholomew and Tucker, 1964). The recent molecular studies of anguimorph lizards by Macey et al. (1997a, 1997b, 1999) suggest that these lizards may possess some features of interest 
TABLE 1

List of Extant Species of Varanus, Taken in Part from Kluge (m.s.) and Bennett (1995)

\begin{tabular}{|c|c|c|c|}
\hline Species of Varanus & Subgenus & Voucher No. & Geography \\
\hline acanthurus Boulenger, 1885 & Odatria & AM R143881 & N \& Central Australia \\
\hline albigularis (Daudin, 1802) & Empagusia & - & S Africa \\
\hline auffenbergi ${ }^{1}$ Sprackland, 1999 & Odatria & - & \\
\hline baritji King and Horner, 1987 & Odatria & UMMZ 222676 & $\mathrm{~N}$ Australia \\
\hline beccari ${ }^{2 a}$ (Doria, 1802) & Odatria & UMFS 10371 & Aru Islands \\
\hline bengalensis ${ }^{3}$ & Indovaranus & & SE Asia, Indonesian islands \\
\hline bengalensis (Daudin, 1802) & & PZ 300941 & \\
\hline nebulosis (Gray, 1831) & & ROM 35017 & \\
\hline bogerti ${ }^{2 a}$ Mertens, 1950 & Euprepiosaurus & - & Louisiade Archipelago \\
\hline brevicauda Boulenger, 1898 & Odatria & - & Australia \\
\hline caerulvirens $^{2 b}$ Ziegler, Böhme, and Phillipp, 1999 & Euprepiosaurus & - & Indonesian islands \\
\hline caudolineatus Boulenger, 1885 & Odatria & - & Australia \\
\hline cerambonensis $^{2 b}$ Philipp, Böhme, and Ziegler, 1999 & Euprepiosaurus & - & Indonesian islands \\
\hline doreanus $^{2 b}$ (Meyer, 1874) & Euprepiosaurus & UMFS 10296 & Papua New Guinea \\
\hline dumerilii (Schlegel, 1839) & Tectovaranus & UMFS 10375 & SE Asia, Sumatra, Borneo \\
\hline eremius Lucas and Frost, 1895 & Odatria & AM R147247 & Australia \\
\hline exanthematicus (Bosc, 1792) & Empagusia & UMFS 10959 & Central Africa \\
\hline finschi $i^{2 b}$ Böhme and Ziegler, 1994 & Euprepiosaurus & - & N Australia and S Papua New Guinea \\
\hline flavescens (Hardwicke and Gray, 1827) & Empagusia & UF 67500 & SE Asia \\
\hline giganteus (Gray, 1845) & Varanus & UMFS 10960 & Central Australia \\
\hline gilleni Lucas and Frost, 1895 & Odatria & AM R147264 & Central Australia \\
\hline glauerti Mertens, 1957 & Odatria & UMFS 10370 & NW Australia \\
\hline glebopalma Mitchell, 1955 & Odatria & UMMZ 218497 & NW Australia \\
\hline gouldii ${ }^{4}$ (Gray, 1838) & Varanus & AM R123634 & Australia \\
\hline griseus & Psammosaurus & & N Africa, Central Asia \\
\hline caspius (Eichwald, 1831) & & - & \\
\hline griseus (Daudin, 1803) & & UMMZ 221342 & \\
\hline koniecznyi Mertens, 1954 & & - & \\
\hline \multirow[t]{3}{*}{ indicus $^{2 b}$ (Daudin, 1802) } & Euprepiosaurus & AM 36431 & N Australia, Papua \\
\hline & & AM 51525 & New Guinea, \\
\hline & & AM R137997 & Indonesian islands \\
\hline jobiensis ${ }^{2 b}$ Ahl, 1932 & Varanus & UMMZ 211713 & Papua New Guinea \\
\hline keithhornei (Wells and Wellington, 1985) & Euprepiosaurus & QM 70792 & NE Australia \\
\hline kingorum Storr, 1980 & Odatria & UMMZ 219012 & NW Australia \\
\hline komodoensis Ouwens, 1912 & Varanus & $\mathrm{NZP}^{*}$ & Indonesian islands \\
\hline melinus ${ }^{2 b}$ Böhme and Ziegler, 1997 & Euprepiosaurus & UMFS 10164 & Indonesian islands \\
\hline mertensi Glauert, 1951 & Varanus & AM R123877 & N Australia \\
\hline mitchelli Mertens, 1958 & Odatria & UMMZ 210576 & $\mathrm{~N}$ Australia \\
\hline niloticus (Linnaeus, 1766) & Polydaedalus & UMMZ 221377 & S \& Central Africa \\
\hline olivaceus Hallowell, 1857 & Phillipisaurus & UMMZ 210202 & Luzon Island \\
\hline panoptes $^{3,4}$ & Varanus & & Australia, Papua New Guinea \\
\hline horni Böhme, 1988 & & UMFS 10157 & \\
\hline panoptes (Gray, 1838) & & UMMZ 210491 & \\
\hline rubidus Storr, 1980 & & - & \\
\hline pilbarensis Storr 1980 & Odatria & WAM R132659 & W Australia \\
\hline prasinus (Schlegel, 1839) & Euprepiosaurus & UMFS 10684 & Papua New Guinea \\
\hline primordius Mertens, 1942 & Odatria & UMMZ 218495 & N Central Australia \\
\hline rosenbergi Mertens, 1957 & Varanus & - & S Australia \\
\hline rudicollis (Gray, 1845) & Dendrovaranus & UMMZ 210506 & SE Asia, Borneo, Indonesian islands \\
\hline salvadorii (Peters and Doria, 1878) & Papusaurus & UMFS 10294 & Papua New Guinea \\
\hline
\end{tabular}


TABLE 1- Continued

\begin{tabular}{|c|c|c|c|}
\hline Species of Varanus & Subgenus & Voucher No. & Geography \\
\hline salvator $^{3}$ & Varanus & & SE Asia, Borneo \\
\hline andamanensis Deraniyagala, 1944 & & - & Philippines, \\
\hline bivittatus (Kuhl, 1820) & & UMFS 10670 & Indonesian islands \\
\hline cumingi Martin, 1838 & & UMFS 10369 & \\
\hline marmoratus (Wiegmann, 1834) & & - & \\
\hline nuchalis (Günther, 1872) & & - & \\
\hline salvator (Laurenti, 1768) & & UMFS 10374 & \\
\hline togianus 5 (Peters, 1872) & & UMFS 10298 & \\
\hline \multirow[t]{2}{*}{ scalaris ${ }^{6}$ Mertens, 1941} & Odatria & UMMZ 218493 & N Australia, S \\
\hline & & AM R138712 & Papua New Guinea \\
\hline semiremex Peters, 1869 & Odatria & AZ-1 & NE Australia \\
\hline spenceri Lucas and Frost, 1903 & Varanus & UMMZ 218500 & Central Australia \\
\hline spinulosis $^{2 b}$ Mertens, 1941 & Euprepiosaurus & - & Solomon Islands \\
\hline storri Mertens, 1966 & Odatria & AM R143912 & $\mathrm{N}$ and Central Australia \\
\hline telenesetes $^{2 a}$ Sprackland, 1991 & Euprepiosaurus & - & Louisade Archipelago \\
\hline timorensis (Gray, 1831) & Odatria & WAM R107008 & Timor, Semau, Savu \\
\hline tristis (Schlegel, 1839) & Odatria & AM R143919 & Australia \\
\hline varius (Shaw, 1790) & Varanus & AM R133492 & SE Australia \\
\hline yemenensis Böhme, Joger, and Schätti, 1989 & Empagusia & - & Yemen, Saudi Arabia \\
\hline yuwono ${ }^{2 b}$ Harvey and Barker, 1997 & Euprepiosaurus & UMMZ 225545 & Halmahera Island \\
\hline
\end{tabular}

Note. If a voucher number is listed, the species was sampled for this study; dashes indicate that the species was not sampled. Voucher number institution key: AM, Australian Museum of Natural History; AZ, Australia Zoo; CAS, California Academy of Sciences; NZP, National Zoological Park (*komodoensis specimen now at the Ueno Zoo, Japan); PZ, Philadelphia Zoo; QM, Queensland Museum; ROM, Royal Ontario Museum; UF, University of Florida; UMFS/UMMZ, University of Michigan Museum of Zoology; WAM, Western Australian Museum. Numbers by species names refer to the following comments:

1 auffenbergi may be a synonym for timorensis.

${ }^{2}$ These species in the prasinus (2a) and indicus (2b) groups have recently been referred to the new subgenus Euprepiosaurus (Böhme et al., 1994; Sprackland, 1994).

${ }^{3}$ These subspecies may represent distinct species.

${ }^{4}$ The nomenclatural changes to flavirufus, gouldii, and panoptes proposed by Böhme (1991) are not reflected because of counterarguments by H. Cogger and G. Shea (pers. comm.).

${ }^{5}$ salvator togianus, initially described as togianus (Peters, 1872), is probably a separate species (A. Kluge, pers. comm).

${ }^{6}$ AM R138712 was initially identified as timorensis.

in the study of specific mechanisms of molecular evolution, such as parallel evolution of duplication and deletion events.

However, the study of Varanus evolution has been hampered by a (largely) non-monophyletic subgeneric taxonomy and the lack of a well-sampled, well-corroborated phylogenetic hypothesis. Although reconstruction of monitor lizard history has been attempted from several sources of evidence, including karyotypes (King and King, 1975), electrophoretic phenotypes (Holmes et al., 1975), male intromittant organ morphology (Branch, 1982; Böhme, 1988; Card and Kluge, 1995), skeletal elements (Estes et al., 1988), ecological and physiological characteristics (Losos and Greene, 1988), lung morphology (Becker, 1991), DNA sequence data
(Baverstock et al., 1993; Fuller et al., 1998), and various combinations of characteristics (King, 1990; King et al., 1991; Sprackland, 1991), these studies differ considerably in their conclusions and no well-corroborated consensus phylogeny has emerged. Specific areas that need testing include the relationships among the African, Indo-Asian, and Indo-Australian species, whether the subgenera Varanus and Odatria are monophyletic, the relationships within Australian endemics (the large-bodied gouldii group and the small-bodied Odatria), and whether the subgeneric taxonomy reflects phylogeny.

The earliest studies of Varanus employing biochemical data include that of Holmes et al. (1975), who combined the chromosome work of King and King (1975) 
with isozyme electrophoretic data to broadly test phylogeny, biogeography, and taxonomy. Using a phenetic analysis of a few characters, these investigators suggested that the African species and Indo-Australian species each arose from the Indo-Asian monitors of the salvator group (including bengalensis, flavescens, and rudicollis). In the African radiation, griseus (found in central Asia and Asia Minor as well as northern Africa) was considered to have given rise to niloticus and exanthematicus, which then radiated southward into Africa. In the Indo-Australian radiation, Odatria was thought to have initially colonized Australia and subsequently given rise to the gouldii group, with a possible second radiation into Australia by an indicus-varius group separately descended from the ancestors of Odatria. Because prasinus and its relatives were not included, Holmes et al. and King and King could not determine the karyomorph or isozyme affinities of this group, which also has an Indo-Australian distribution. Holmes et al. and King and King noted that the traditional taxonomy probably did not reflect natural groups within Varanus.

Sprackland (1991) focused primarily on the origin and monophyly of Odatria and whether species of the prasinus group were part of this assemblage, using the data of Holmes et al. (1975) combined with additional morphological and ecological characters. Based on his preferred cladogram, Sprackland suggested that the African species were basal to the rest of Varanus and that the Indo-Asian taxa formed a cline between the African species and the monophyletic Indo-Australian clade. Odatria was monophyletic and had possibly evolved from the gouldii group through a salvator-like ancestor (contra King and King, 1975). Sprackland's hypothesis also demonstrated that prasinus and its relatives were more closely related to indicus than Odatria. Sprackland's data were later reanalyzed by Card and Kluge (1995), who determined that his conclusions regarding prasinus and Odatria monophyly were corroborated, but that no resolution of the relationship between the gouldii group and Odatria could be obtained using this data set.

Baverstock et al.'s (1993) analysis also broadly examined relationships within Varanus. Based on reciprocal microcomplement fixation testing of a limited number of taxa, they identified three major clades of Varanus: an African clade, a clade of the large-bodied Indo-
Asian and Indo-Australian taxa, and Odatria. Because outgroup material either was unavailable or failed to fix in cross-reactions with Varanus, the authors could not root their tree and the relationships among these lineages went undetermined. In the Indo-Asian and -Australian clade, the Indo-Australian species mertensi, rosenbergi, and salvadorii were sister to a clade of IndoAsian species. Baverstock et al. hypothesized two separate invasions of Australia, as the Australian endemics (Odatria and the gouldii group) were not sister taxa. A phylogenetic hypothesis based on both reciprocal and one-way comparisons, with a more inclusive set of species, additionally suggested that Australia had been invaded at least three times and corroborated Sprackland's (1991) proposition that prasinus is closely related to the indicus complex rather than to Odatria. Baverstock et al. followed King and King (1975) in noting the shortcomings of the traditional subgeneric classification of Varanus.

More recently, DNA sequence data were used by Fuller et al. (1998) to attempt to resolve the biogeographic origins of Varanus. Their study was based on two nonoverlapping segments of the mitochondrial $12 S$ ribosomal RNA gene (about 700 bp total) and included Heloderma and Lanthanotus as outgroup taxa. Parsimony analysis resulted in a single most parsimonious tree suggesting that the African species are sister to the rest of Varanus, the Indo-Asian species form a paraphyletic assemblage, and the Indo-Australian species are a clade. Subgenus Varanus (represented by the gouldii group and indicus, salvator, komodoensis, and varius) was polyphyletic, and Odatria was paraphyletic with the gouldii group nested within it, although loglikelihood ratio and nonparametric parsimony (Wilcoxon matched-pairs signed-ranks) tests suggested that the topology of the best overall hypothesis was not significantly worse than one in which each of the subgenera Varanus and Odatria were constrained to monophyly. Additionally, prasinus was shown to be related to olivaceus rather than to indicus or any odatrian species.

A consensus phylogeny based on these studies is largely unresolved. To date, there is no single wellsupported hypothesis of relationships for Varanoidea and Varanus, and the current subgeneric taxonomy of Varanus (Table 1) apparently does not reflect phylogeny. Incomplete taxonomic sampling within studies 
and differential sampling among studies have certainly contributed to these shortcomings, as many of the previously mentioned works sampled incompletely within Varanus or did not sample its nearest relatives. Thorough taxonomic sampling is necessary to ensure that the data are maximally informative, to reduce the potential for long-branch artifacts (Hillis, 1998; Graybeal, 1998), and to encompass a complete picture of history. The present study extensively samples the diversity of Varanoidea and results in a well-corroborated phylogenetic hypothesis that will further the investigation of the evolution and biogeography of these remarkable lizards.

\section{MATERIALS AND METHODS}

Taxonomic sampling. Forty-eight individuals of Varanus were sequenced, representing each of the currently recognized subgenera (see Table 1 for a list of species sampled, subgeneric classification, voucher numbers, and general geographic localities). Some species were sampled from different localities (indicus, $p a-$ noptes, and the subspecies of salvator). A specimen initially misidentified as timorensis was reidentified as scalaris. Other varanoids sampled include the monotypic lanthanotid L. borneensis (no accession number), the taxon most closely related to Varanus (corroborated by both morphological and molecular data; e.g., Rieppel, 1980, and Fuller et al., 1998), and the two extant helodermatids H. horridum (UMFS 10134) and H. suspectum (no accession number), considered to be sister to Lanthanotus + Varanus (Pregill et al., 1986). Outgroup taxa Anguis fragilis (CAS 190559), Anniella pulchra (CAS B15p556), and Elgaria kingi (UMFS 10107) were selected to represent Anguioidea, the putative sister taxon to Varanoidea (Camp, 1923; reviewed by Rieppel, 1988).

DNA extraction, amplification, and sequencing. Genomic DNA was extracted from fresh, frozen, or ethanol-preserved muscle or liver tissue or bufferpreserved blood samples with QIAamp tissue kits (Qiagen) as per the manufacturer's instructions. One extract that did not immediately amplify (kingorum) was cleaned of proteins and other PCR inhibitors by centrifugation through a Centricon-30 column (Amicon); after this treatment, the extract amplified normally.
The 2.8-kb region sequenced spans the $3^{\prime}$ end of the $16 \mathrm{~S}$ rRNA gene to the $5^{\prime}$ region of $\mathrm{CO}-1$ and includes the complete sequences of ND-1, ND-2, and nine

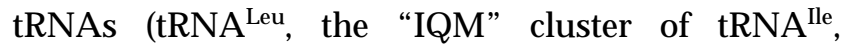
$\mathrm{tRNA}^{\mathrm{Gln}}$, and tRNA ${ }^{\mathrm{Met}}$, and the "WANCY" cluster of $\mathrm{tRNA}^{\mathrm{Tr} \mathrm{p}}$, $\mathrm{tRNA}^{\mathrm{Ala}}$, $^{\mathrm{RNNA}}{ }^{\mathrm{Asn}}$, $\mathrm{tRNA}^{\mathrm{Cys}}$, and $\mathrm{tRNA}^{\mathrm{Tyr}}$ ). To further minimize the chances of amplifying nuclear copies, the entire $2.8-\mathrm{kb}$ target region was amplified using long PCR protocols and primers L3827 and H6681 (Sorenson et al., 1999). Smaller fragments were subsequently amplified using standard PCR protocols from the long piece of DNA using primer pairs L3827H4644, L4500-H5191, L4951-H5760, and L5601H6681 (see Sorenson et al., 1999, for primer sequences). The Varanus-specific primers L4951 (5'-CCTCCTCTG AAAACAATTTCTCCC-3'), H5760 (5'-GATGAGGA GTGCTATTGGGGC-3'), and L5601 (5'-TGACTMCC AGAAGTHCTTCAAGG-3') respectively replace the primers L5216, H5766, and L5758 of Sorenson et al. (1999), providing a better match to template DNA and a more substantial region of overlap between contiguous fragments. DNA from two species, flavescens and primordius, did not amplify across the entire region, and primers L3827 and H5766 (Sorenson et al., 1999) were used for long-product amplification; the sequence for these taxa therefore terminates at about halfway through ND-2. The lack of amplification might be attributed to poor DNA quality for flavescens, in which the tissue sample was somewhat degraded, but is less explicable in primordius, as a sample of a different individual also did not amplify using any primer to the $5^{\prime}$ side of H5766.

PCR products were electrophoresed through agarose gels, visualized with ethidium bromide staining, removed from the gel, and purified using a QIAamp gel extraction kit (Qiagen). Light and heavy strands were both sequenced using dye terminators (Perkin-Elmer) and analyzed with an ABI 377 automated sequencer. Primer sequences were trimmed from chromatograms and the individual sequences were assembled by overlapping each sequenced PCR product into a single contiguous segment. Protein-coding genes were identified and aligned by inferred amino acid sequences, and tRNAs were identified and aligned by stem and loop sections of the secondary structure in each sequence (Lynch, 1996). All sequences can be found in GenBank (AF407488-AF407541). 
Phylogenetic analysis. The $2.8-\mathrm{kb}$ sequences were parsed into 13 gene sequences for analysis (partial 16S rRNA, ND-1, ND-2, nine tRNAs, and partial CO-1). The short region of $16 \mathrm{~S}$ sequenced comprised stem regions constant across all taxa and highly variable loop regions and was therefore excluded from the analysis. Intergenic spacer regions were excluded from all analyses, as were uninformative characters and sites where alignment was nontrivial (primarily tRNA loops), leaving 1474 parsimony-informative sites. The few (32) gapped regions that remained were considered to be potentially informative (as suggested by Giribet and Wheeler, 1999), and gaps were treated as a fifth base.

For the primary analysis, all informative sites were weighted equally (for rationale see Results and Discussion). Because one region of a sequence pairs with another region on the same strand in stem and loop structures, as are found in tRNAs, it could be argued that a change in one base in one stem region must necessitate a compensatory change in the pairing site of the second region, and therefore to count each pair of a stem region would have artificially inflated the number of informative characters. However, mutations resulting in stem mispairings are not unusual in animal mitochondrial tRNAs (Lynch, 1996, pers. obs.), so sequences of both strands in a given stem were used. Data were analyzed simultaneously in PAUP* $4.0 \mathrm{~b} 4$ (Swofford, 1999) with 1000 heuristic search replicates; initial trees were randomly generated and swapped using tree bisection-reconnection. Jackknife values were calculated with PAUP* emulating JAC resampling (Farris et al., 1996) for 1000 replicates with 20 heuristic searches per replicate. Bremer support values (Bremer, 1994) were calculated using TreeRot (Sorenson, 1999) and PAUP* with 20 heuristic searches per node examined. Searches were also run in which third codon position transitions were weighted to zero and in which third positions were eliminated altogether. Heuristic and jackknife searches for these two analyses were computed as above with 100 replicates.

Two separate data partitions were analyzed using the incongruence length difference test (ILD, Mickevitch and Farris, 1981; Farris et al., 1994, 1995) as implemented by XARN (Farris, 1996) and the partition homogeneity test in PAUP*. The first partition tested for incongruence among first, second, and third codon positions in the protein-coding genes, and the second tested for incongruence among genes (ND-1, ND-2, CO-1, and the combined tRNAs). The Mickevitch/ Farris (M/F) incongruence statistic was calculated by determining the shortest length for each partition and the number of extra steps needed to find the best fitting cladogram in the combined analysis (as per Mickevitch and Farris, 1981; Kluge, 1989). For analyses of most character sets in each partitioned analysis, minimum length was calculated with 100 heuristic replicates with the same settings as used for the simultaneous analysis. One of the data classes, CO-1, had a small number of informative characters (16); minimum and reconstructed length for CO-1 was calculated using tree bisection-reconnection swapping on the most parsimonious tree obtained from the simultaneous analysis. The length obtained by this procedure is not guaranteed to be minimal, but an overestimate of the shortest length for that partition can only overestimate the $\mathrm{M} / \mathrm{F}$ statistic, and the small number of steps that the CO-1 partition contributes means that a small difference in this number will not significantly affect the value of the statistic.

\section{RESULTS AND DISCUSSION}

\section{Sequence Identity}

Mitochondrial DNA sequences are known to have transferred to nuclear DNA in many taxa (Zhang and Hewitt, 1996; Sorenson and Fleischer, 1996), potentially confounding to phylogenetic analysis if nuclear pseudogenes are analyzed along with true mitochondrial genes. The methods employed and results obtained in this study indicate that the sequences are indeed mitochondrial in origin. The use of mitochondria-enriched tissue, mitochondrial-sequence-specific primers, and an initial amplification of a large segment of DNA helps ensure that these sequences are not nuclear (Sorenson and Quinn, 1998). The absence of premature stop codons in ND-1 and ND-2 suggests that these regions produce functional $\mathrm{mRNA}$ transcripts, and the stable secondary structures of the tRNAs also suggest that these tRNAs function in translating mRNA. In addition, no sequence differences are found between contiguous, overlapping PCR products for any species, 


\section{TABLE 2}

Summary of Base Composition of 52 Taxa (Excluding flavescens and primordius, which Lack Sequence for the Second Half of ND-2 and WANCY tRNAs)

\begin{tabular}{lllll}
\hline & \multicolumn{1}{c}{$\mathrm{A}$} & \multicolumn{1}{c}{$\mathrm{T}$} & \multicolumn{1}{c}{$\mathrm{C}$} & \multicolumn{1}{c}{$\mathrm{G}$} \\
\hline Range & $0.29-0.39$ & $0.19-0.28$ & $0.25-0.43$ & $0.06-0.12$ \\
Mean & 0.33 & 0.23 & 0.36 & 0.08 \\
\hline
\end{tabular}

demonstrating that a single long product was initially amplified. The absence of unusually short branches on the most and near-most parsimonious hypotheses also implies that no nuclear sequences were accidentally recovered. The base composition of each taxon for the sequenced region is biased against guanine (Table 2), found to be typical of anguid mitochondrial proteincoding and tRNA genes, but not nuclear genes (e.g. Macey et al., 1999).

\section{tRNA ${ }^{\text {Cys }}$ and the Origin of Light-Strand Replication}

In all Varanus sequenced, the last three bases of the origin of light-strand replication overlap with the first three bases of the aminoacyl (AA) stem in tRNA ${ }^{\text {Cys }}$, as has been observed throughout squamates (Macey et al., 1997b, 1999). The 3'-GCC-5' region that initiates light-strand elongation in $\mathrm{Mus}$ (Brennicke and Clayton, 1981 ) is present; the $3^{\prime}-\mathrm{GBCCB}-5^{\prime}$ consensus sequence suggested by Macey et al. (1997b) to be related to the $3^{\prime}$ GGCCG-5' necessary for genome replication in Homo
(Hixson et al., 1986) is different among most genera sequenced (Table 3). In all Varanus species, the D-arm of $\mathrm{tRNA}{ }^{\mathrm{Cys}}$ has been replaced by a nonpairing region of 3-7 bp. E. kingi has a single basepairing that may represent a truncated stem, also noted by Macey et al. (1999). Lanthanotus has a 3-bp stem, while Ang. fragilis, Ann. pulchra, and both species of Heloderma have a 4bp stem (Macey et al. reported slightly different numbers of stem bases for Anniella and H. suspectum). The 4-base tandem repeat reported by Macey et al. (1997b, 1999) to occur in and around the D-arm for griseus does not appear to be necessarily conserved in Varanus; the specimen of g. griseus sequenced for this study lacks this specific repeat (Fig. 1), and other Varanus lack a $>$ 2-bp evenly spaced repeat entirely. The African and Asian species of Varanus also have the 6-bp stem and 2-bp loop of the T-arm in tRNA ${ }^{\text {Cys }}$ noted by Macey et al. (1999); however, the Australian species generally have shorter stems, varying from 3 to 5 bases, and larger loops, varying from 1 to 7 bases.

\section{Phylogeny of Varanus}

A single most parsimonious cladogram results from simultaneous analysis of all 1474 informative characters (Fig. 2, CI $=0.246$, $\mathrm{RI}=0.487$ ). This hypothesis is generally well supported. Bremer support and consistency and retention indices were determined for the separate genes and from different functional regions of the genes; these measures demonstrate that all site classes contribute support, and homoplasy in this data

\section{TABLE 3}

Aligned Consensus Structures of the Stem and Loop Region of the $\mathrm{O}_{\mathrm{L}}$

\begin{tabular}{|c|c|c|c|}
\hline Taxon & $5^{\prime}$ stem & & $3^{\prime}$ stem \\
\hline Anguis and Elgaria & CTTCTCCCGTT & (7) & AACGGGAGAAGCCCCGGA \\
\hline Anniella & CTTCTCCCGTT & (10) & AACGGGAGAAGCCCGGGA \\
\hline Heloderma & СTTCTCCCGCC & (6) & AACGGGAGAAGTTCCGGG \\
\hline Lanthanotus and Varanus & CTTCTCCCGT $_{2-7}$ & $\left(\mathrm{R}_{5-12}\right)$ & $\mathrm{A}_{2-7}$ CGGGAGAAGYCCAGGG \\
\hline
\end{tabular}

Note. The numbers in parentheses indicate the number of bases in the loop. Subscript numbers show the variation in stem size in Varanus and Lanthanotus. The total length of the $\mathrm{O}_{\mathrm{L}}$ varies from 28 (Heloderma) to 44 (varius). In Lanthanotus and some Varanus, $\mathrm{G}$ replaces the $5^{\prime}$-most $\mathrm{A}$ in the $3^{\prime}$-most stem. Underline indicates the 5'-CGG-3' region demonstrated by Brennicke and Clayton (1981) to initiate light-strand replication in Mus; dotted underline indicates the 5-base region reported by Macey et al. (1997b) to complement the heavy-strand sequence 3'-GGCCG-5' in tRNA ${ }^{\text {Cys }}$ necessary for light-strand replication (Hixson et al., 1986). Boldface indicates the overlap between the 3'-most $\mathrm{O}_{\mathrm{L}}$ stem and $\mathrm{RNA}^{\mathrm{Cys}}$. Some variable sites in the stem are labeled with standard one-letter code: $\mathrm{R}=\mathrm{A}, \mathrm{G} ; \mathrm{Y}=\mathrm{C}, \mathrm{T}$. 
A

Varanus griseus (Macey et al. 1997a)

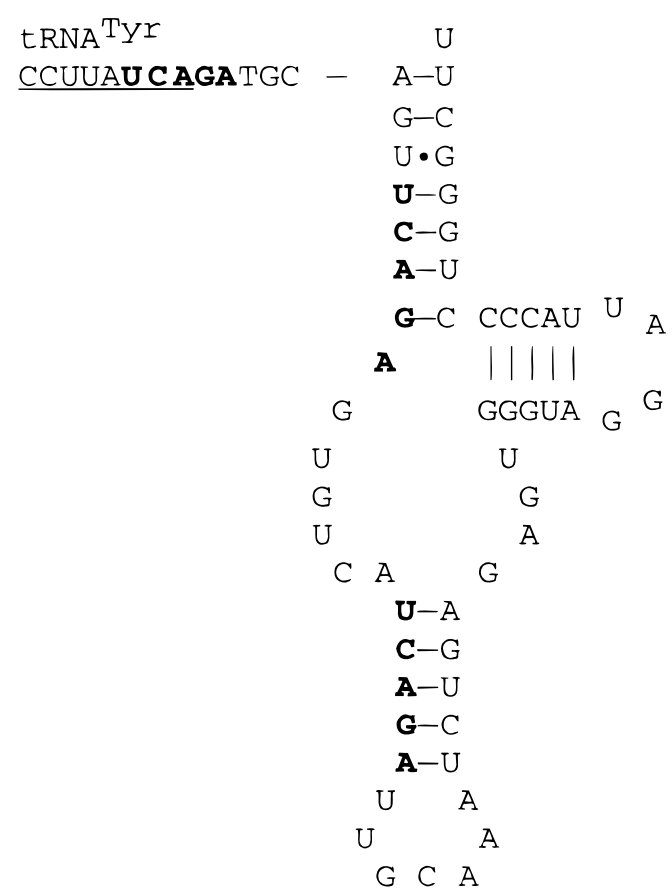

B

Varanus griseus griseus (this study)

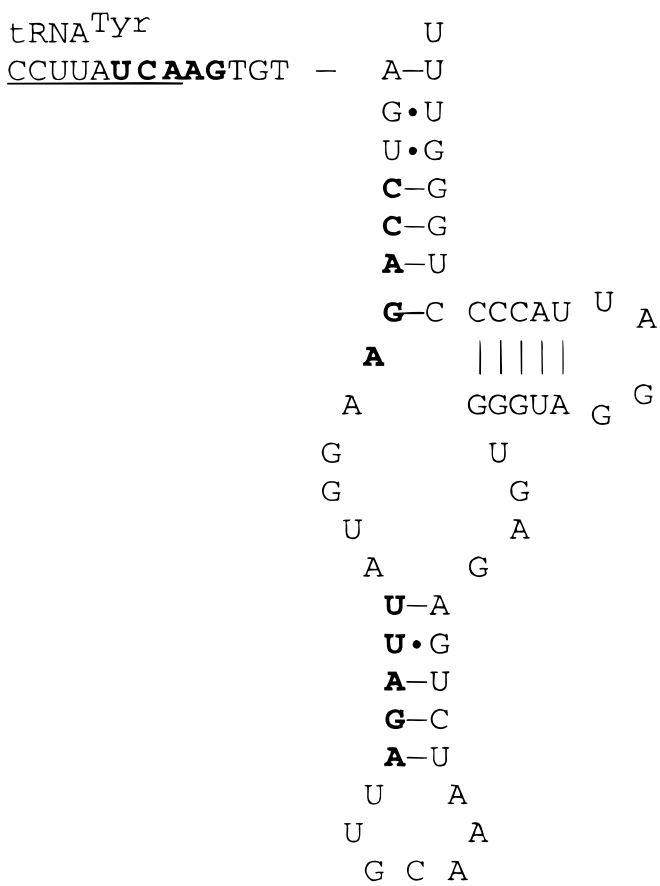

FIG. 1. Inferred secondary structure of tRNA ${ }^{C y s}$ for two individuals of Varanus griseus (A, Macey et al., 1997a, Fig. 4; B, this study) represented as $5^{\prime}$ to $3^{\prime}$ RNA transcript and showing the D-arm replacement loop typical of squamates. Underlined region represents the adjacent aminoacyl stem of $\mathrm{tRNA}^{\mathrm{Tyr}}$. Boldface indicates tandem repeats found by Macey et al. (1997a) lacking in the individual sequenced for this study.

set is attributable mainly to differences within the recognized classes of data, not between them (Table 4). Varanus is strongly supported as monophyletic (Bremer support $=105$, jackknife support $=1.00$ ), as is the close relationship between Lanthanotus and Varanus (Bremer support $=51$, jackknife support $=1.00$ ) and the monophyly of Varanoidea (Heloderma, Lanthanotus, and Varanus; Bremer support $=42$, jackknife support $=1.00)$.
Within Varanus, three major lineages (African, IndoAsian, and Indo-Australian) are delimited. The African species form a group sister to the rest of Varanus, while the Indo-Asian clade is sister to the Indo-Australian clade. The Indo-Asian group, weakly supported as monophyletic, comprises two distinct clades, labeled A and B in Fig. 2. Group A includes terrestrial Asian forms, such as bengalensis, and the water monitors of the salvator complex. The subspecies of salvator form a

FIG. 2. Most parsimonious hypothesis based on simultaneous analysis of 1474 informative characters $($ length $=11,274, \mathrm{CI}=0.246$, $\mathrm{RI}=$ 0.487), with species ranges noted (NT, Northern Territory (Australia); PNG, Papua New Guinea). Outgroup taxa not shown. Boldface line indicates the Varanus clade, in which only the species name is given. Numbers above branch are Bremer support; numbers below the branch are the percentage node recovery in a parsimony jackknife analysis (see Materials and Methods). Indo-Asian group A consists of mainland Asian and southeast island species, while those in Indo-Asian group B are found primarily in New Guinea (with the exception of olivaceus, which is found only in the Philippines). 


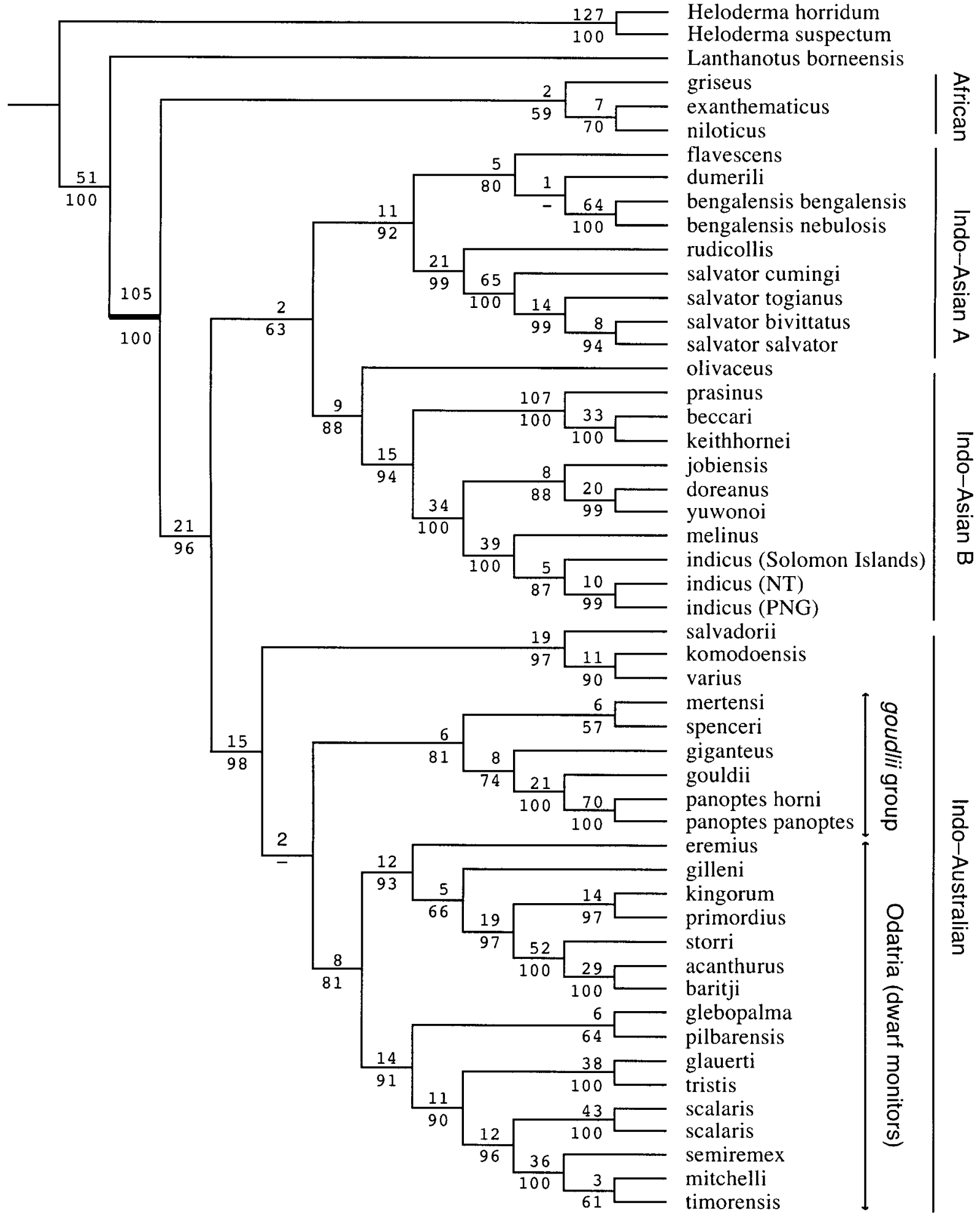




\section{TABLE 4}

Indices of Each of the Two Partition Sets

\begin{tabular}{lrrrcc}
\hline \multicolumn{1}{c}{ Site class } & $n$ & Steps & BI & CI & RI \\
\hline First positions & 356 & 2,067 & 213 & 0.322 & 0.552 \\
Second positions & 203 & 905 & 201 & 0.316 & 0.587 \\
Third positions & 651 & 6,991 & 635 & 0.206 & 0.430 \\
tRNA stems & 241 & 1,152 & 208 & 0.301 & 0.589 \\
tRNA loops & 24 & 159 & 31 & 0.258 & 0.524 \\
ND-1 (total) & 502 & 4,284 & 547 & 0.224 & 0.459 \\
ND-2 (total) & 691 & 5,507 & 456 & 0.253 & 0.484 \\
CO-1 (total) & 16 & 172 & 45 & 0.198 & 0.469 \\
tRNAs (total) & 265 & 1,311 & 240 & 0.296 & 0.582 \\
Simultaneous & 1474 & 11,274 & 1288 & 0.246 & 0.487 \\
\hline
\end{tabular}

Note. In the first set, data are partitioned by the presumed function of sites within genes (five categories) and in the second data are partitioned among genes (four categories). Indices were calculated from the most parsimonious hypothesis using combined data. Rows show indices for each category in the partition: $n$, number of parsimony-informative sites; steps, length on the most parsimonious hypothesis; BI, Bremer support (fractional values have been rounded); $\mathrm{CI}$ and RI, ensemble consistency and retention indices, respectively.

distinct and strongly supported monophyletic clade (Bremer support $=65$, jackknife $=1.00$ ). In Group B, the herbivorous olivaceus is sister to a clade that includes the arboreal prasinus group and the mangrove monitors (indicus complex) (Bremer support $=15$, jackknife support $=0.94)$. The mangrove monitors form a distinct lineage (Bremer support $=34$, jackknife $=1.00$ ) that includes the species doreanus, jobiensis, melinus, and yuwonoi, all of which were initially described as subspecies of indicus.

The Indo-Australian species are well supported as a single lineage (Bremer support $=15$, jackknife $=1.00$ ), within which three major clades may be discerned. The lace monitor varius, restricted to eastern Australia, is not closely related to the other large Australian monitors, but rather to the clade including the Komodo dragon komodoensis (found on Flores, Komodo, and nearby small islands) and the crocodile monitor salvadorii (endemic to New Guinea). This group is sister to the Australian endemics, which includes both large(giganteus and the gouldii group) and small-bodied lizards (subgenus Odatria). The low support value for the node that unites the gouldii group and Odatria reflects a tree two steps longer in which the gouldii group forms a clade with the (also large-bodied) komodoensis- salvadorii-varius clade. In either case, Odatria appears to be the monophyletic (Bremer support $=8$, jackknife $=0.81$ ) sister taxon to a clade of much larger relatives. Within Odatria, there is strong support for monophyly of the spiny-tailed group (acanthurus, baritji, kingorum, primordius, and storri, BI $=19$, jackknife $=0.97$; this group is also noted by Baverstock et al. (1993)). The reidentification of the "timorensis" from Australia's Northern Territory is corroborated by this specimen's close relationship to scalaris rather than to a correctly identified timorensis from Timor.

\section{Comparison to Previous Phylogenetic Hypotheses}

The network of relationships among major groups suggested by King and King (1975) and Holmes et al. (1975) is similar to the network in my phylogeny (Fig. 2), although the rooting and therefore inferred direction of chromosome change are quite different. These authors recognize the gouldii group (their group A, the Australian members of subgenus Varanus, with some intragroup allozyme variation), a group including indicus and varius $(\mathrm{B}$, not recovered in the present study), a salvator group ( $\mathrm{C}$, including bengalensis, flavescens, and rudicollis), Odatria (D), and separate griseus (E) and niloticus-exanthematicus (F) groups. King and King (1975, p. 104) infer the direction of evolution by estimating the "primordial form" to be the most common, simplest karyomorph, as represented by group $\mathrm{C}$, with 7 large metacentric chromosome pairs, 1 subacrocentric large chromosome pair, and 12 acrocentric microchromosome pairs. According to King and King's network of relationships, 4 of the large chromosomes have accumulated 11 pericentric inversions and tend toward acrocentricity, while the microchromosomes have independently evolved metacentricity twice. The slightly different network proposed by Holmes et al. (1975) requires one less inversion in the large chromosome 5. Given their hypothesized ancestral condition in Varanus, mapping onto my cladogram requires 11 inversions in the large chromosomes and 3 in the microchromosomes; however, most lizard species have metacentric rather than acrocentric microchromosomes (King and King, 1975), and if the ancestral condition is metacentricity, then only 2 inversions are required. 
The hypotheses resulting from the analyses of Baverstock et al. (1993), Card and Kluge (1995), and Fuller et al. (1998) are all similar in several ways, although the differences in taxonomic sampling render them not directly comparable. In general, they identify an African group, at least two separate Indo-Asian groups, the gouldii group, and Odatria. Baverstock et al.'s (1993) unrooted hypothesis has a basal polytomy of four groups: the African species, the Indo-Asian and large Indo-Australian species, Odatria (excluding eremius), and eremius alone; the relationships within these groups are generally similar to those found by my DNA analysis. Card and Kluge's (1995) consensus tree has too many polytomies to suggest relationships among the larger groups, although the close relationships they identify between prasinus and indicus and between Odatria and the large Indo-Australian species are corroborated by my hypothesis. The hypothesis of Fuller et al. (1998), also based on mitochondrial DNA sequences, is similar to mine in several respects, such as the placement of the African species sister to all other Varanus species, resolution of two Indo-Asian clades, and resolution within the Indo-Australian taxa (salvadorii-komodoensis-varius sister to the gouldii group + Odatria). Differences include their placement of indicus outside my Indo-Asian B group and acanthurus (an odatrian) sister to the gouldii group.

\section{Taxonomy}

I agree with Baverstock et al. (1993, p. 629), who note that the taxonomy of Varanus, as proposed by Mertens (1942), has little to commend it in light of recent evidence. Currently 10 subgenera are officially recognized, of which 2 (Varanus and Odatria) comprise many species, 1 (Empagusia) comprises a few species, and 7 (see below) are monotypic. In addition, I recognize Böhme et al.'s (1994) and Sprackland' s (1994) resurrection of subgenus Euprepiosaurus although the name has yet to regain its formal status.

Subgenus Varanus includes large Australian and some Indonesian taxa and is clearly polyphyletic. The Australian species of subgenus Varanus (excluding varius) are monophyletic (the gouldii group), but each of the other species in this subgenus (komodoensis, varius, and the salvator complex) is more closely related to other lineages than they are to one another. Monophyly of Odatria is strongly supported if Mertens' placements of prasinus in Odatria (1942) and mitchelli in subgenus Varanus (1958) are reassessed; the removal of prasinus and the inclusion of mitchelli are clearly warranted if taxonomy is to reflect well-corroborated relationships. Glebopalma is also an odatrian, despite osteological characters that suggest its affinity with subgenus Varanus rather than Odatria (A. Kluge, pers. comm.). As flavescens is related to other Asian species rather than exanthematicus (to which it bears a superficial resemblance), Empagusia is polyphyletic. All monotypic subgenera (Dendrovaranus for rudicollis, Indovaranus for bengalensis, Papusaurus for salvadorii, Phillipinosaurus for olivaceus, Polydaedalus for niloticus, Psammosaurus for griseus, and Tectovaranus for dumerili) are clearly associated with other species, and the use of these names at the subgeneric rank should be reconsidered. Many sources of evidence corroborate monophyly of Euprepiosaurus, which comprises the prasinus and indicus species groups (Sprackland, 1991, 1994; Böhme et al., 1994).

\section{Homoplasy and Data Congruence}

The problem of homoplasy in sequence data is of increasing concern to systematists as the potential for within-data incongruence has become more apparent. Homoplasy as measured by incongruence can have several possible causes and is thought to inevitably result when evolutionary rates at different functional sites are heterogeneous. However, a comparison of the consistency and retention indices shows that no given partition set performs notably better or worse than any other. In neither partition analysis is incongruence more pronounced between given partitions sets than it is within a partition set, and the null hypothesis (that each of the partition sets is biased toward different tree topologies) is rejected by the ILD test (codon partition, $\mathrm{M} / \mathrm{F}=0.0197$, real ILD $=1.0, P<0.001$; gene partition, $\mathrm{M} / \mathrm{F}=0.0165$, real ILD $=1.0, P<0.001)$. Partition homogeneity performs a similar test from the opposite point of view (the null hypothesis being that the data are homogeneous across partitions), and in this test the null hypothesis cannot be rejected for either partition $(P=0.38$ and $P=0.32$, respectively; see Allard et al. (1999) for a discussion of how ILD and partition homogeneity test results compare). A graph of the partitioned Bremer support value of each node for the most parsimonious hypothesis (Fig. 3) demonstrates 


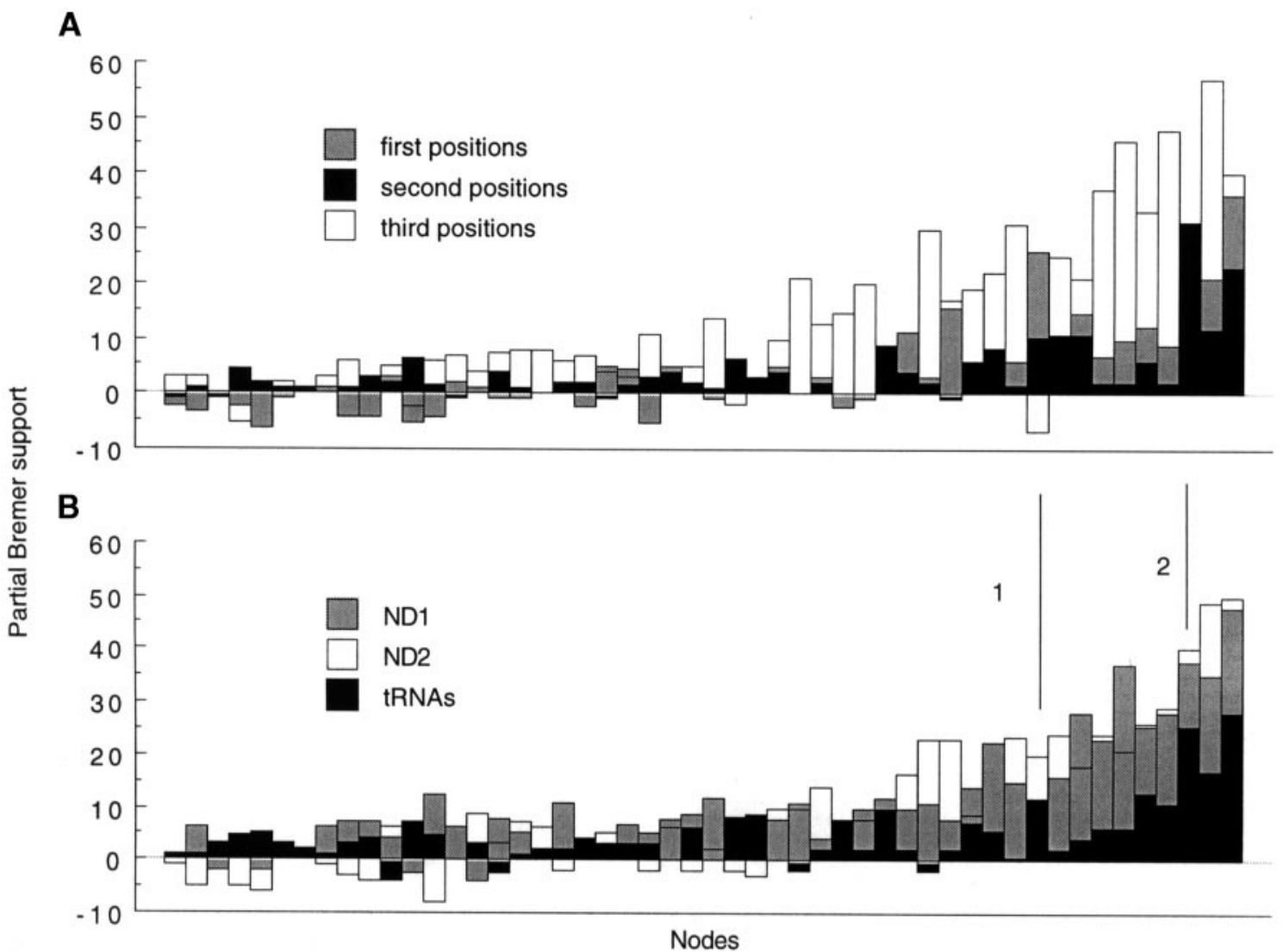

FIG. 3. Graph showing partitioned branch support at nodes for the two partition sets: (A) first, second, and third codon positions, and (B) ND-1, ND-2, and the nine tRNAs combined (CO-1 not included). Both graphs are ordered by increasing total branch support on the total evidence tree. Line 1 indicates the node for Varanoidea; line 2 indicates the Varanus node. Positive numbers indicate that the given partition contributes to support at that node; negative numbers indicate that the given partition favors an alternative hypothesis.

that, at most nodes, support from each partition was positive; however, some conflict between partitions can be seen at nodes in which support is positive for one character set and negative for another.

As an extension of the rate heterogeneity argument, incongruence in a phylogenetic hypothesis is also thought to necessarily result from the more rapidly changing sites being saturated with change. That data are saturated is often used as a basis for downweighting, excluding, or transforming data before a phylogenetic analysis is performed, the rationale being that such data have suffered multiple substitutions at each site and the phylogenetic signal has been overwritten (e.g. Swofford et al., 1996). A plot of the transitions and transversions for the different partitions reveals that most of the data do not have a profile typical of satu- rated data, with the exception of third position transitions (Fig. 4), in which the amount of change is no longer positively correlated with increasing genetic distance.

When transitions in the third codon positions are weighted to zero, the resulting two equally parsimonious hypotheses differ from that of the simultaneous analysis in placing the gouldii group as sister to the salvadorii-komodoensis-varius clade, resolving a slightly different relationship of glebopalma and pilbarensis in Odatria and producing uncertain resolution among salvator bivittatus, s. salvator, and s. togianus. When third codon positions are eliminated altogether, two different most parsimonious hypotheses result, the consensus of which results in additional resolution loss within Odatria. Jackknife support lessens or disappears for 
A

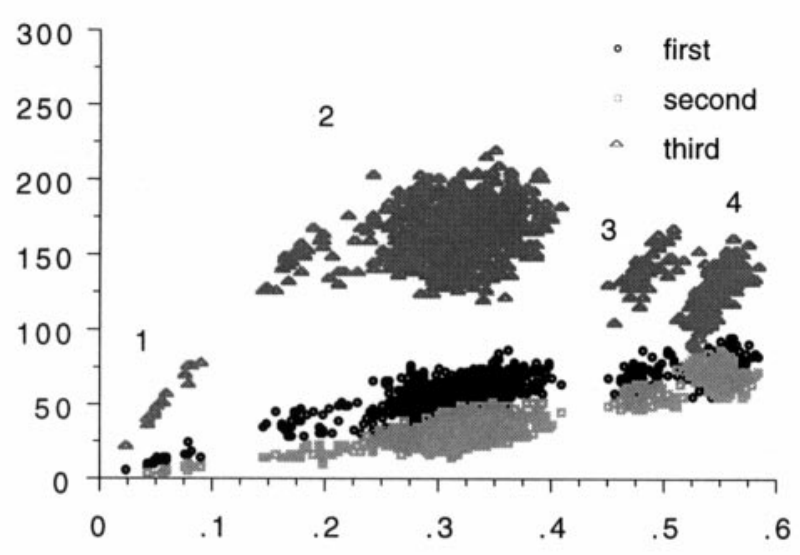

B

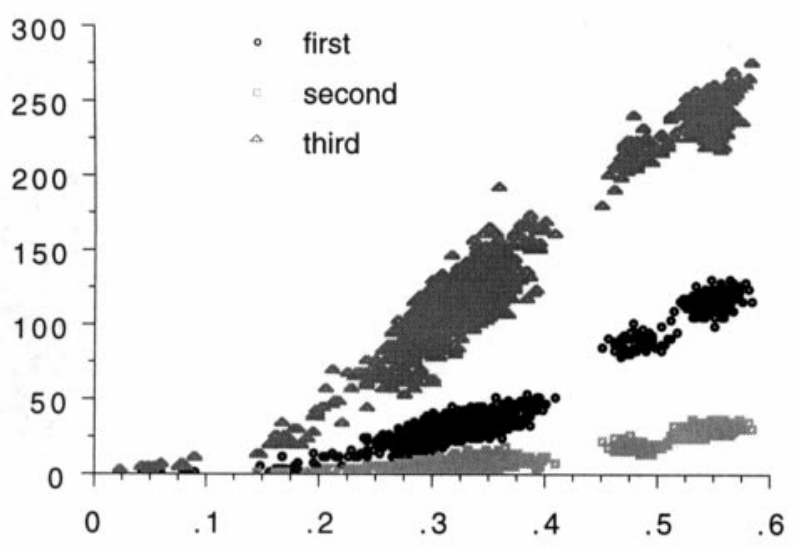

C

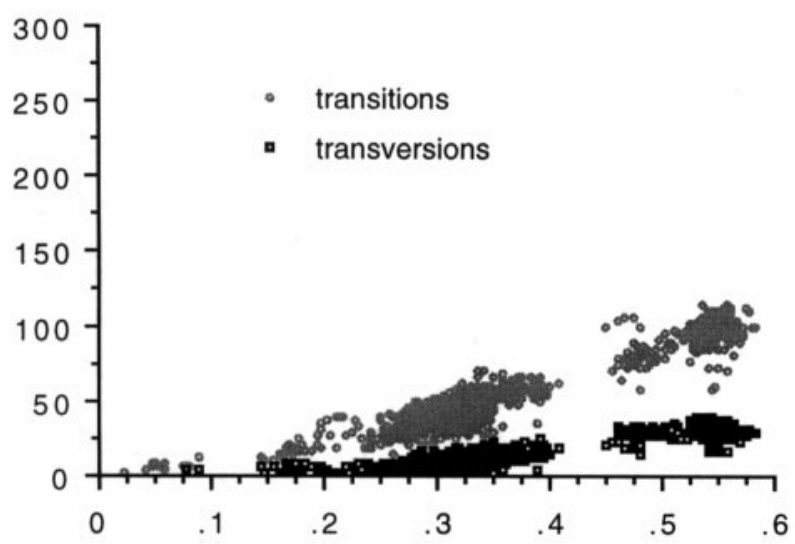

several intermediate and recent nodes in both of these searches. These results are not especially surprising given that the third positions contribute nearly half of the informative characters and more than half of the total tree length (Table 3). Change is indisputably more frequent in third positions than in first or second codon positions or tRNAs.

However, relative frequency of change alone is not a reliable predictor of phylogenetic informativeness (Björklund, 1999; Källersjö et al., 1999; Sennblad and Bremer, 2000), and percentage sequence divergence or saturation curves alone may not reflect whether phylogenetic structure remains present. When taxonomic sampling includes both recent and ancient nodes, as does the present analysis, rapidly changing characters (such as the third codon positions) will provide support to the relatively recent nodes, while the more slowly changing sites (such as the second codon positions) will support the deeper nodes. That the rapidly changing characters may be relatively incongruent at deeper nodes does not necessarily interfere with overall tree resolution, or overwhelm the analysis with incongruence, as long as other characters are present to resolve these older nodes (for review see Allard et al., 1999). In the present analysis, the tRNA and first and second codon changes are providing the needed support at the more ancient nodes, such as those delimiting Varanoidea and Varanus (Fig. 3).

The sequence data used in this study demonstrate that heterogeneous evolutionary rates are not necessarily detrimental to phylogenetic analysis. The lower CI and RI values for third positions (Table 3) indicate that these data are more homoplastic than other classes of characters, and the saturation curve (Fig. 4) demonstrates that at least transitions in the third codon position occur frequently enough to have been replaced multiple instances in the time since the divergence

\footnotetext{
FIG. 4. Graphs of transitions (A) and transversions (B) at each codon position and transitions and transversions in the tRNAs (C). Note four distinct groups of points, which represent different groups of taxa: (1) closely related taxa, such as the indicus and salvator complexes, and the two individuals of scalaris and panoptes; (2) Varanus species compared to other Varanus species; (3) Lanthanotus compared to Varanus; (4) Varanus compared to Heloderma and the outgroup taxa.
} 
of anguioids and varanoids. Nevertheless, when the rapidly evolving characters are eliminated from the analysis, several equally parsimonious hypotheses result and support at many nodes is drastically diminished. This reduction in both resolution and support indicates that rapidly evolving regions can contribute positively to a hypothesis, a fact not immediately evident if data are eliminated a priori and not first analyzed in a phylogenetic context.

\section{AC KNOWLEDGMENTS}

I thank the following people and institutions for tissue samples of Varanus species: Arnold Kluge (University of Michigan Museum of Zoology), Ross Sadlier (Australian Museum of Natural History), Gavin Bedford (Northern Territory University), John Dell (Western Australian Museum), Patrick Couper (Queensland Museum), Bob Murphy (Royal Ontario Museum), Bill Holmstrom (Bronx Zoo), Trooper Walsh, Michael Davenport, Don Nichols, and Elaine Lamirande (National Zoological Park), Reg Hoyt and Kevin Wright (Philadelphia Zoo), Kelsey Engle (Australia Zoo), Kamerun Tepedelen (Bushmaster Reptiles), Frank Retes (Goanna Ranch), Tammie Bettinger (Cleveland Metroparks Zoo), Winston Card (Dallas Zoo), and Tim, Susan, and Joseph Scott; outgroup samples were provided by Johnny Arnett (Cincinnati Zoo), Eric Pianka (Universtiy of Texas), Tod Reeder (San Diego State University), Robin Lawson (California Academy of Sciences), and Brad Moon (University of Michigan). For creative and unerring laboratory advice I thank Derek Dimcheff, Michael Sorenson, and David Mindell. Arnold Kluge and Mark Norell provided helpful comments on earlier versions of this article. Financial support was provided by the University of Michigan Block Grant (Department of Biology), Hinsdale-Walker Grant (UMMZ), and Dissertation-Thesis Grant (Rackham School of Graduate Studies).

\section{REFERENCES}

Allard, M. W., Farris, J. S., and Carpenter, J. M. (1999). Congruence among mammalian mitochondrial genes. Cladistics 15, 75-84.

Bartholomew, G. A., and Tucker, V. A. (1964). Size, body temperature, thermal conductance, oxygen consumption and heart rate in Australian varanid lizards. Physiol. Zool. 37, 341-354.

Baverstock, P. R., King, D., King, M., Birrell, J., and Krieg, M. (1993). The evolution of species of the Varanidae: Microcomplement fixation analysis of serum albumins. Aust. J. Zool. 41, 621-638.
Becker, H. O. (1991). The lung morphology of Varanus yemenensis (Böhme, Joger and Schatti) and its bearing on the systematics of the Afro-Asian monitor radiation. Mertensiella 2, 29-37.

Björklund, M. (1999). Are third positions really that bad? A test using vertebrate cytochrome b. Cladistics 15, 191-197.

Böhme, W. (1988). Zur Genitalmorphologie der Savria; Functionelle und stammesgeschichtliche Aspekte. Bonn. Zool. Beitr. 40, 27-56.

Böhme, W. R., Horn, H.-G., and Ziegler, T. (1994). Zur Taxonomie der Pazifikwarane (Varanus indicus-Komplex): Revalidierung von Varanus doreanus (A. B. Meyer, 1874) mit Beschreibung einer neuer Unterart. Salamandra 30, 119-142.

Branch, W. R. (1982). Hemipeneal morphology of platynotan lizards. J. Herpetol. 16, 16-38.

Bremer, K. (1994). Branch support and tree stability. Cladistics 10, 295-304.

Brennicke, A., and Clayton, D. A. (1981). Nucleotide assignments of alkali-sensitive sites in mouse mitochondrial DNA. J. Biol. Chem. 256, 10613-10617.

Camp, C. L. (1923). Classification of the lizards. Bull. Am. Mus. Nat. Hist. 48, 289-435.

Card, W., and Kluge, A. G. (1995). Hemipeneal skeleton and varanid systematics. J. Herpetol. 29, 275-280.

Carroll, R. L., and deBraga, M. (1992). Aigialosaurs: Mid-Cretaceous varanoid lizards. J. Vert. Paleo. 12, 66-86.

De Salle, R., and Brower, A. V. Z. (1997). Process partitions, congruence, and the independence of characters: Inferring relationships among closely related Hawaiian Drosophila from multiple gene regions. Syst. Biol. 46, 751-764.

Estes, R. K. (1983). The fossil record and early distribution of lizards. In "Advances in Herpetology and Evolutionary Biology" (A. Rhodin and K. Miyata, Eds.), pp. 365-391. Museum of Comparative Zoology, Cambridge, MA.

Estes, R., de Queiroz, K., and Gauthier, J. (1988). Phylogenetic relationships within Squamata. In "Phylogenetic Relationships of the Lizard Families" (R. Estes and G. Pregill, Eds.), pp. 119-281. Stanford Univ. Press, CA.

Farris, J. S. (1996). XARN. Naturhistoriska riksmuseet, Stockholm.

Farris, J. S., Albert, V. A., Källersjö, M., Lipscomb, D., and Kluge, A. G. (1996). Parsimony jackknifing outperforms neighbor-joining. Cladistics 12, 99-124.

Farris, J. S., Källersjö, M., Kluge, A. G., and Bult, C. (1994). Testing significance of incongruence. Cladistics 10, 315-319.

Farris, J. S., Källersjö, M., Kluge, A. G., and Bult, C. (1995). Constructing a significance test for incongruence. Syst. Biol. 44, 570-572.

Fuller, S., Baverstock, P., and King D. (1998). Biogeographic origins of goannas (Varanidae): A molecular perspective. Mol. Phylogenet. Evol. 9, 294-307.

Gao, K., and Norell, M. A. (2000). Taxonomic composition and systematics of Late Cretaceous lizard assemblages from Ukhaa Tolgod and 
adjacent localities, Mongolian Gobi Desert. Bull. Am. Mus. Nat. Hist. 249, 1-118.

Giribet, G., and Wheeler, W. (1999). On gaps. Mol. Phylogenet. Evol. 13, 132-143.

Graybeal, A. (1998). Is it better to add taxa or characters to a difficult phylogenetic problem? Syst. Biol. 47, 9-17.

Harvey, M. B., and Barker, D. G. (1998). A new species of blue-tailed monitor lizard (genus Varanus) from Halmahera Island, Indonesia. Herpetology 54, 34-44.

Hillis, D. M. (1998). Taxonomic sampling, phylogenetic accuracy, and investigator bias. Syst. Biol. 47, 3-8.

Hixson, J. E., Wong, T. W., and Clayton, D. A. (1986). Both the conserved and divergent 5 '-flanking sequences are required for initiation at the human mitochondrial origin of light strand replication. J. Biol. Chem. 261, 2384-2390.

Holmes, R. S., King, M., and King, D. (1975). Phenetic relationships among varanid lizards based upon comparative electrophoretic data and karyotypic analyses. Biochem. Syst. Ecol. 3, 257-262.

Källersjö, M., Albert, V. A., and Farris, J. S. (1999). Homoplasy increases phylogenetic structure. Cladistics 15, 91-93.

King, D., King, M., and Baverstock, P. (1991). A new phylogeny of the Varanidae. Mertensiella 2, 211-219.

King, M. (1990). Chromosomal and immunogenetic data: A new perspective on the origins of Australia's reptiles. In "Cytogenetics of Amphibians and Reptiles" (E. Olmo, Ed.), pp. 153-180. Birkhäuser Verlag, Basel.

King, M., and King, D. (1975). Chromosomal evolution in the lizard genus Varanus (Reptilia). Aust. J. Biol. Sci. 28, 89-108.

Kluge, A. G. (1989). A concern for evidence and a phylogenetic hypothesis of relationships among Epicrates (Boidae, Serpentes). Syst. Biol. 38, 7-25.

Kumazawa, Y., Ota, H., Nishida, M., and Ozawa, T. (1996). Gene rearrangements in snake mitochondrial genomes: Highly concerted evolution of control-region-like sequences duplicated and inserted into a tRNA cluster. Mol. Biol. Evol. 13, 1242-1254.

Losos, J. B., and Greene, H. W. (1988). Ecological and evolutionary implications of diet in monitor lizards. Biol. J. Linnean Soc. 35, 379-407.

Lynch, M. (1996). Mutation accumulation in transfer RNAs: Molecular evidence for Muller's ratchet in mitochondrial genomes. Mol. Biol. Evol. 13, 209-220.

Macey, J. R., Larson, A., Anajeva, N. B., and Papenfuss, T. J. (1997a). Replication slippage may cause parallel evolution in the secondary structure of mitochondrial transfer RNAs. Mol. Biol. Evol. 14, 3039.

Macey, J. R., Larson, A., Anajeva, N. B., Fang, Z., and Papenfuss, T. J. (1997b). Two novel gene orders and the role of light-strand replication in rearrangement of the vertebrate mitochondrial genome. Mol. Biol. Evol. 14, 91-104.

Macey, J. R., Schulte, J. A., II, Larson, A., Tuniyev, B. S., Orlov, N., and Papenfuss, T. J. (1999). Molecular phylogenetics, tRNA evolution, and historical biogeography in anguid lizards and related taxonomic families. Mol. Phylogenet. Evol. 12, 250-272.
Mertens, R. (1942). Die Familie der Warane (Varanidae). Dritte Teil: Taxonomie. Abh. Senck. Naturf. Ges. 466, 235-391.

Mertens, R. (1958). Bemerkungen über die Warane Australiens. Senck. Biol. 39, 229-264.

Mickevitch, M. F., and Farris, J. S. (1981). The implications of congruence in Menidia. Syst. Zool. 30, 351-370.

Miyamoto, M. M., and Cracraft, J. (1991). Phylogenetic inference, DNA sequence analysis, and the future of molecular systematics. In "Phylogenetic Analysis of DNA Sequences" (M. M. Miyamoto and J. Cracraft, Eds.), pp. 3-17. Oxford Univ. Press, New York.

Norell, M. A., and Gao, K. (1997). Braincase and phylogenetic relationships of Estesia mongoliensis from the Late Cretaceous of the Gobi Desert and the recognition of a new clade of lizards. Am. Mus. Novitates 3211, 1-25.

Pesole, G., Gissi, C., De Chirco, A., and Saccone, C. (1999). Nucleotide substitution rate of mammalian mitochondrial genomes. J. Mol. Evol. 48, 427-434.

Pianka, E. (1995). Evolution of body size: Varanid lizards as a model system. Am. Nat. 146, 398-414.

Pregill, G. K., Gauthier, J. A., and Greene, H. W. (1986). The evolution of helodermatid squamates, with a description of a new taxon and an overview of Varanoidea. Trans. San Diego Soc. Nat. Hist. 21, 167-202.

Rieppel, O. (1980). The phylogeny of anguimorph lizards. Denkschr. Schweiz. Naturforsch. Ges. 94, 94-86.

Rieppel, O. (1988). The classification of the Squamata. In "The Phylogeny and Classification of the Tetrapods, Volume 1: Amphibians, Reptiles, and Birds" (M. J. Benton, Ed.), pp. 261-293. Clarendon, Oxford.

Sennblad, B., and Bremer, B. (2000). Is there a justification for differential a priori weighting in coding sequences? A case study from $r b c L$ and Apocyanaceae s. 1. Syst. Biol. 49, 101-113.

Sorenson, M. D. (1999). TreeRot, version 2. Boston University, Boston, MA.

Sorenson, M. D., Ast, J. C., Dimcheff, D. E., Yuri, T., and Mindell, D. P. (1999). Primers for a PCR-based approach to mitochondrial genome sequencing in birds and other vertebrates. Mol. Phylogenet. Evol. 12, 105-114.

Sorenson, M. D., and Fleischer, R. C. (1996). Multiple independent transpositions of mitochondrial DNA control region sequences to the nucleus. Proc. Natl. Acad. Sci. USA 93, 15239-15243.

Sorenson, M. D., and Quinn, T. W. (1998). Numts: A challenge for avian systematics and population biology. The Auk 115, 214-221.

Sprackland, R. (1991). The origin and zoogeography of monitor lizards of the subgenus Odatria Gray (Sauria: Varanidae): A re-evaluation. Mertensiella 2, 240-252.

Sprackland, R. (1994). Rediscovery and taxonomic review of Varanus indicus spinulosis, Mertens, 1941. Herpetofauna 24, 33-39.

Swofford, D. L. (1999). PAUP*: Phylogenetic Analysis Using Parsimony (beta version). Sinauer, Sunderland, MA. 
Swofford, D. L., Olsen, G. J., Waddell, P. J., and Hillis, D. M. (1996). Phylogenetic inference. In "Molecular Systematics" (D. M. Hillis, C. Moritz, and B. K. Mable, Eds.), 2nd ed., pp. 407-514. Sinauer, Sunderland, MA.
Wheeler, W. (1996). Optimization alignment: The end of multiple sequence alignment in phylogenetics? Cladistics 12, 1-9.

Zhang, D.-X., and Hewitt, G. M. (1996). Nuclear integrations: Challenges for mitochondrial DNA markers. TREE 11, 247-251. 